\title{
The Potential of Anti-IgE in Food Allergy Therapy
}

\author{
Monali Manohar, PhD \\ Kari C. Nadeau, MD, PhD*
}

\author{
Address \\ * Department of Pediatrics, Division of Immunology and Allergy, Stanford University, \\ 300 Pasteur Drive, Stanford, CA 94305, USA \\ Email: knadeau@stanford.edu
}

Published online: 21 March 2014

(C) Springer International Publishing AG 2014

Keywords Food allergy - Anaphylaxis - IgE - Omalizumab - Oral immunotherapy - Oral food challenge • Desensitization - Tolerance

\section{Opinion statement}

Food allergy is an inappropriate immune response to certain food components. With its increasing prevalence over the past two decades, and potentially fatal consequences, food allergy has become a formidable public health issue. There is currently no effective therapy to treat food allergy. Patients are compelled to resort to strict avoidance of allergenic foods, and they must have quick access to emergency care in the event of accidental exposure. Clearly, there is an urgent need for treatment options. Allergenspecific and allergen-nonspecific therapeutic measures are being actively explored through ongoing research. The data thus far have identified the promise of oral immunotherapy (OIT) among allergen-specific and anti-IgE administration among allergennonspecific treatment modes. Indeed, results from three recent trials employing anti$\mathrm{IgE}$ as an adjunctive therapy with OIT have indicated an outstanding potential to safely and rapidly desensitize patients with severe food allergies. The existing data set, however, is severely limited and is derived from diverse study designs that, in turn, have individual shortcomings. Readouts from current and proposed multicenter clinical trials following a well-designed uniform treatment protocol will be highly valuable for carrying out comparative analysis and to draw concrete inferences that will pave the way for approved food allergy therapy.

\section{Introduction}

Food allergy is the result of immune response-driven adverse health effects that occur reproducibly on exposure to a given food. Symptoms of food allergy emerge as immediate (within 2 hours) or delayed (within 6-72 hours) gastrointestinal, dermatological, respiratory, or cardiovascular reactions, potentially culminating in fatal or near-fatal incidents of anaphylaxis. The current cumulative prevalence for food allergy in adults and children is estimated at $5 \%$ and $8 \%$, respectively, and is reportedly on a continuous rise. Therefore, food allergy has become a serious public health concern and warrants critical interven- 
tion [1-3].Foods with most commonly encountered food allergens include milk, eggs, peanuts, soy, wheat, tree nuts, fish, and shellfish. Adverse reactions to a food allergen can be either IgE-mediated or nonIgE mediated. This review focuses on IgE-mediated food allergies.

\section{Immune mechanism of IgE-mediated food allergy}

Under the IgE-mediated pathway, on primary exposure, antigen-presenting cells capture, process, and present cognate food allergen/s to naïve T cells, resulting in the polarization of the T cells toward Th2 phenotype. These allergen-specific Th2 cells secrete large amounts of IL-4 and IL-13, which in turn promote antibody class switching and differentiation of B cells into plasma cells secreting IgE antibodies, which recognize that food allergen/s. Free IgE in plasma binds to its high-affinity receptor- FceRI, expressed by basophils and mast cells (Fig. 1a). On re-exposure, the cognate food allergen is recognized by cell-bound IgE, triggering downstream signaling cascade leading to degranulation of basophils and mast cells. Chemical mediators such as histamines, leukotrienes, and prostaglandins released during the degranulation process give rise to the aforementioned adverse health effects $[2,4,5]$.

Double-blind placebo-controlled oral food challenge (DBPCFC) has been described as the gold standard in clinical diagnosis of food allergy. In this method, the patient ingests gradually increasing amounts of food to which sensitization is suspected, or an unrelated food (placebo). Elicitation of allergic symptoms on consumption of food allergen versus lack of any such symptoms with placebo affirm food allergy.

Immune response measurement through skin prick test and estimation of allergen-specific IgE, in conjunction with the patient's medical history and physical examination, can aid physicians in providing care to food allergy patients. In the skin prick test, a microscopic amount of food allergen is introduced into the patient's skin through a pinprick. The response is recorded in terms of diameter of wheal, which reflects food allergen-induced mast cell degranulation, thus demonstrating prior sensitization. Allergenspecific IgE levels are estimated via commercially available sandwich assays $[6,7]$. Although useful in identifying foods that may provoke IgE-mediated allergic reactions, the skin prick test, either alone or in combination with allergen-specific IgE, is not recommended to confirm diagnosis of food allergy [1].

\section{Current treatment options}

Despite the recognition that food allergy is a major public health issue, there are no effective treatment options or curative strategies currently available for food allergy patients. The accepted standard of care is limited to strict avoidance of allergenic foods, nutritional counseling, and access to rapid 
a

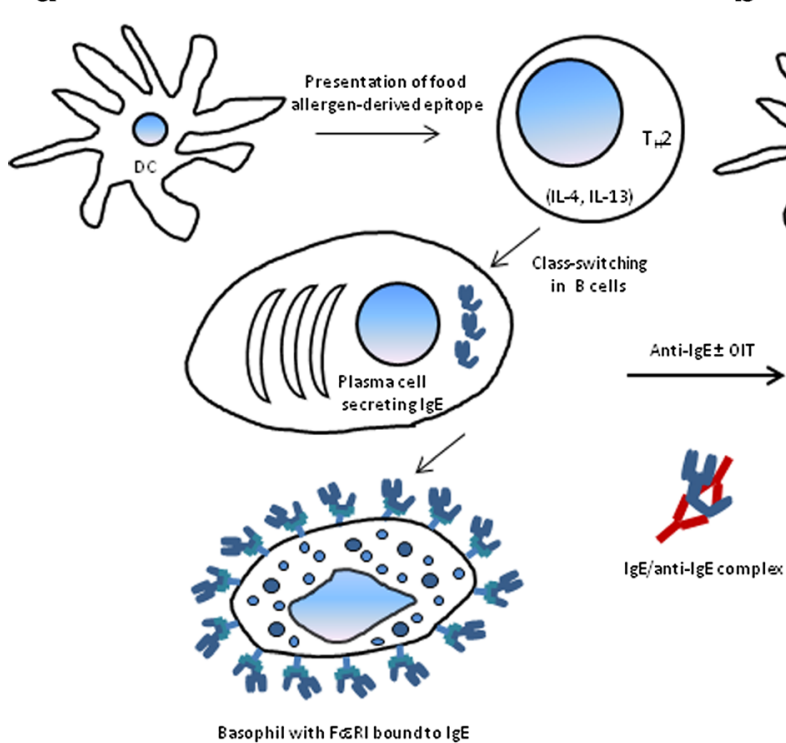

b

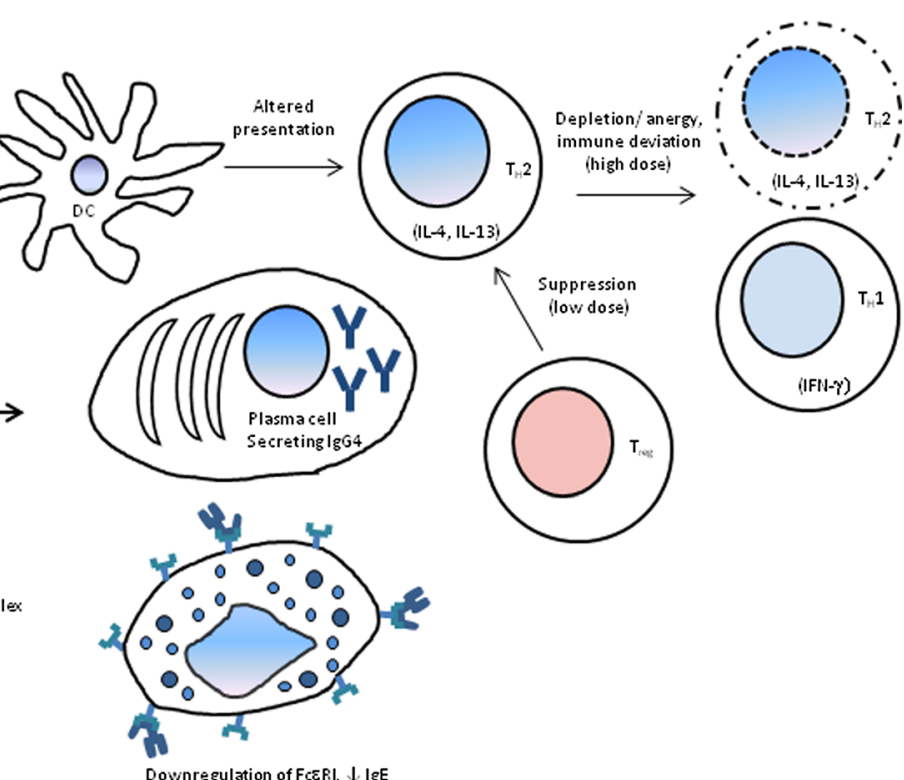

Figure 1. Immune mechanism of food allergy and post-treatment desensitization. In IgE-mediated food allergy, primary exposure to a food leads to development of high levels of food allergen-specific IgE, which binds to FcERI on the surface of basophils (a). On re-exposure, degranulation of basophils ensuing recognition of cognate food allergen-derived epitope by IgE gives rise to allergic symptoms. Anti-IgE molecules form a biologically inert complex with IgE. Anti-IgE + OIT combination therapy has been shown to bring about depletion of or anergy in Th2 cells, with concomitant re-polarization/ immune deviation toward Th1 direction. While this effect is attributed to high-dose administration during combination therapy, desensitization through 0IT alone with relatively low allergen doses is more likely driven by increased suppression by Treg cells. Anti-IgE treatment leads to down-modulation of FcERI expression on basophils. In addition, decrease in the levels of allergen-specific $\mathrm{IgE}$, and significant increase in those of IgG4, tends to imply successful desensitization (b), with alleviation of allergy symptoms as the net clinical outcome.

emergency care (i.e., ready availability of epinephrine autoinjector) to alleviate acute symptoms in the event of accidental exposure. Strict adherence to allergen avoidance is complicated by instances of undeclared food allergens in commercial food preparations as well as lapses in awareness of ingredients on the part of the food preparer or consumer. Therefore, there is always the threat of accidental exposure and ensuing allergic reaction, which in turn has a significant negative impact on psychosocial well-being of susceptible individuals and their families $[8,9]$.

This issue is being addressed by exploring novel therapeutic approaches aimed at inducing desensitization, with the eventual goal of developing tolerance to allergenic food/s. These approaches can be classified as allergenspecific and allergen-nonspecific.

\section{Allergen-specific therapy}

Allergen-specific therapy consists of administration of small amounts of food allergen to the patient through oral, sublingual, epicutaneous, or subcuta- 
neous route. Of these methods, the most promising results thus far have been obtained with oral immunotherapy (OIT) [10-12]. Generally, an initial DBPCFC confirming the allergic status of the patient to the cognate food allergen precedes initiation of OIT. An "initial-day dose escalation" marks the first day of OIT, where the patient is administered increasing amounts of food allergen over 6-8 hours under clinical supervision to establish the highest tolerated dose. This dose is administered as the starting dose during the consecutive "build-up" or "dose-escalation" phase, with gradual weekly or biweekly increase until a targeted maintenance dose is reached. The patient continues to consume the maintenance dose of the food allergen throughout the third and final "maintenance phase" spanning a few weeks to months. A post-treatment final oral food challenge (OFC) evaluates the efficacy of the OIT protocol, with success asserted by statistically significant increase in tolerated dose of the food allergen, one that would protect the patient on accidental exposure or, ideally, allow the patient to incorporate normal amounts of that food into his/her daily diet.

Outcomes of various OIT studies undertaken to desensitize patients allergic to milk, egg, and peanuts have previously been reviewed in detail [10-12]. Objective comparative analysis of the results thus far is not feasible due to differences among study designs in terms of patient enrollment criteria, allergen doses, duration of phases, and reported readouts. Nonetheless, a common pattern reveals that while 50-75\% patients are successfully desensitized, 10$25 \%$ achieve only partial desensitization post-therapy. The presence of higher allergen-specific IgE in this subset of patients likely compromises therapeutic desensitization. Also, the majority of patients undergoing desensitization experience at least one adverse reaction over the course of study. The severity of some such reactions highlights the fact that patient safety remains the prime concern in any OIT protocol. Efforts are underway to devise a more effective protocol that tackles these issues.

\section{Allergen-nonspecific therapy}

Allergen-nonspecific approaches include treatment options such as administration of anti-IgE to neutralize IgE or use of Food Allergy Herbal Formula-2 (FAHF-2), a modified version of herbal concoction suggested in Chinese traditional medicine $[13,14]$. This review will focus on the first of these treatment strategies.

Anti-IgE: development and mechanism of action

As described earlier, presence of food allergen-specific IgE in plasma implies sensitization to that food. As allergen crosslinking of FceRI-bound IgE is the first step in triggering the highly sensitive basophil signaling cascade, IgE-FceRI interaction is an obvious target to block pathways leading to anaphylaxis.

As with other immunoglobulins, IgE molecular structure features Fab and Fc regions. Fab fragment is composed of a pair of light chains covalently bound to variable and proximal constant (CE1) domains of heavy chain pair. Fc fragment comprises C $\varepsilon 2, C \varepsilon 3$, and C 84 domains of heavy chain, of which C 83 docks into the $\alpha$ subunit of FceRI [15]. 
With early clinical studies demonstrating efficacy of therapies aimed at reducing IgE load in ameliorating symptoms of asthma and allergy, efforts were undertaken to generate monoclonal anti-IgE antibodies that would specifically interfere with binding of IgE to FceRI. Clones selected based on their binding specificity were humanized to down-modulate antigenicity and thus enable their clinical application. Omalizumab (Xolair ${ }^{\circledR}$; Genentech, South San Francisco, CA, USA), and talizumab (TNX-901; Tanox, Houston, TX, USA) are two such independently developed anti-IgE antibodies $[16,17]$ that have demonstrated success in clinical trials. Although due to multiple lawsuits surrounding patent infringement, talizumab is yet to reach commercial market. Omalizumab, on the other hand, is commercially available and is FDA-approved to treat moderate to severe persistent asthma refractory to inhaled corticosteroids [18].

Through recognition of and ensuing binding to C $\varepsilon 3$ domain of free IgE, omalizumab and talizumab abrogate IgE-FceRI interaction, hence preventing degranulation by basophils and mast cells. The IgE/anti-IgE complexes thus formed are biologically inert and can safely be cleared from circulation without causing immune complex-related reactions. Also, since circulating IgE and signaling cascade initiated by crosslinking of cell-bound IgE can induce the expression of FceRI, blockade by anti-IgE antibodies interrupts this positive feedback loop, thereby increasing the threshold allergen dose for basophil/mast cell activation [19]. In addition to basophils and mast cells, FceRI is also expressed by dendritic cells (DCs), where it is thought to play a role in allergen presentation to T cells. By abrogating FceRI upregulation, omalizumab and talizumab are speculated to down-modulate allergen presentation by DCs, with consequent decrease in Th2 function, thus leading to alleviation of allergic symptoms [20-22].

Thus far only a handful of clinical trials have tested the efficacy of anti-IgE in treating food allergies. Anti-IgE has been used either as monotherapy or adjunctive treatment with OIT. The following is a summary of the results of these studies.

\section{Anti-IgE as monotherapy}

The first study showing the efficacy of anti-IgE treatment in food allergy patients was published by Leung and colleagues in 2003 [23•]. In this multicenter double-blind trial, 84 patients with history of immediate hypersensitivity to peanut (confirmed pre-enrollment by oral food challenge) were randomly assigned in a 3:1 ratio to receive 4 doses of either 150/300/ $450 \mathrm{mg}$ TNX-901 or placebo subcutaneously over 4 weeks. The final oral food challenge conducted 2 to 4 weeks after the fourth dose indicated a trend of dose-dependent improvement in peanut tolerance. The group on the 450mg TNX-901 regimen could tolerate $2805 \mathrm{mg}$ peanut flour vs. $1010 \mathrm{mg}$ tolerated by subjects in the placebo group. This increase in tolerated threshold amount of peanut was found to be statistically significant and enough to confer substantial protection against accidental peanut ingestion. Although encouraging as findings from the first of-its-kind study, the observed improvement was suboptimal to induce desensitization. (This is the only trial examining efficacy of talizumab in food allergy therapy. With the 
development of TNX-901 on hold, further trials were carried out using omalizumab.)

A subsequent phase II parallel-group double-blind placebo-controlled study was designed to extend these findings by evaluating the efficacy of omalizumab in reducing the risk of peanut-induced allergic reactions [24•]. Patients who qualified through an initial screening DBPCFC were administered omalizumab every 2 to 4 weeks over 20-22 weeks. A second DBPCFC was performed at week 24 to evaluate treatment performance. Although this study intended to randomize 150 subjects, it was prematurely terminated due to two severe incidents of anaphylaxis during the initial qualifying oral food challenge. Nevertheless, the data from 14 subjects who completed the therapy and underwent final oral food challenge showed an anti-IgE-mediated increase in peanut tolerability, with $44.4 \%$ of omalizumab-treated patients vs. $20 \%$ of patients in the placebo-treated group able to tolerate $\geq$ $1000 \mathrm{mg}$ of peanut flour. While this trial could not conclusively assert the efficacy of omalizumab, the limited available data was consistent with the overall findings from the TNX-901 trial and justified pursuing anti-IgE as a treatment option for food allergy.

A recent open-label study by Savage et al. with peanut-allergic patients has addressed kinetic and mechanistic details behind omalizumab therapy.

Fourteen subjects were enrolled in the study based on initial DBPCFC, skin prick test titration (SPTT), and basophil histamine release (BHR).

Omalizumab was administered every 2-4 weeks for 24 weeks. Repeat BHR, OFC, and SPTT were carried out at specified time points to evaluate efficacy of treatment. All 10 subjects who completed the study showed statistically significant increase in the threshold tolerated dose of peanut, although only 4 were able to tolerate doses higher than $10,000 \mathrm{mg}$ and hence desensitized [25•]. More importantly, this study unravels a very interesting variation in the kinetics of desensitization of subjects with low vs. high allergen-specific IgE, and suppression of basophil vs. mast cell response. Further analysis of these clinical observations revealed increased intrinsic sensitivity of basophils to IgE-mediated stimulation as a possible factor in compromising the efficacy of omalizumab [26]. Considering the overall variability in the efficacy of anti-IgE as monotherapy, further such studies focused on immune mechanism will be of critical importance to identify "biomarkers" that can help distinguish between potential responders and non-responders [27].

\section{Anti-IgE as adjunctive therapy with OIT}

The need for measures to reduce the severity and frequency of adverse reactions during OIT from the viewpoint of patient safety was highlighted earlier. A 2006 study with ragweed-induced allergic rhinitis first reported the beneficial effects of omalizumab pretreatment, which allowed administration of higher doses of allergen over a short period of time (i.e., rapid desensitization through rush immunotherapy) without compromising patient safety [28]. The rationale from this study was implemented in food allergy therapy

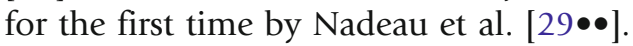

In this phase I pilot study, 11 patients with a history of IgE-mediated milk allergy (median milk-specific IgE of $50 \mathrm{kUA} / \mathrm{L}$ ) were enrolled at two sites. 
Omalizumab was administered every 2 to 4 weeks for 16 weeks. Oral milk desensitization was initiated at week 9 from the start of omalizumab therapy, with rush desensitization on the first day followed by dose-escalation phase. During the rush oral desensitization, increasing doses of milk powder (starting with $0.1 \mathrm{mg}$ to the maximum of $1000 \mathrm{mg}$ ) were administered every 30 minutes. During dose-escalation phase, desensitization was continued with weekly increases in milk dose over the following 7-11 weeks. A DBPCFC at week 24 of the study showed that 9 of 10 patients who completed the study were able to tolerate one full serving of milk. Mean frequency for total adverse reactions was as low as $1.6 \%$, and most reactions were graded mild to moderate $[29 \bullet \bullet]$. There were certain drawbacks to the study, such as small sample size, lack of placebo group, and lack of baseline OFC. Nonetheless, given that the enrolled subjects had very high levels of milk-specific IgE as well as history of severe milk allergy, desensitization affording intake of normal amounts of milk in daily diet (>8000 mg/day) within 4 months of OIT, with only mild reactions, is indeed a remarkable success.

An elegant follow-up study by Bedoret et al. focused on analysis of immune cells of desensitized subjects has provided valuable insights into the mechanism of anti-IgE + OIT-induced tolerance [30••]. The results from this study show induction of anergy in or depletion of milk-specific $\mathrm{CD} 4^{+} \mathrm{T}$ cells during rush desensitization. Interestingly, milk-specific $\mathrm{CD}^{+} \mathrm{T}$ cell response returned during maintenance phase, although it was characterized as Th1biased as opposed to Th2-biased pre-therapy. No changes were seen in frequency or function of regulatory T (Treg) cells. Significant reduction in milkspecific IgE and concomitant increase in milk-specific IgG4 levels, together with downregulated basophil response, reflected desensitization.

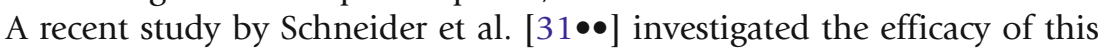
combination therapy in patients allergic to peanuts. Thirteen subjects (median peanut-specific IgE of $229 \mathrm{kUA} / \mathrm{L}$ ), who failed the initial DBPCFC at peanut flour $\leq 100 \mathrm{mg}$ were enrolled in the study. Omalizumab was administered every 2-4 weeks over 20 weeks. Oral desensitization was initiated at week 12 of omalizumab therapy. During the rush desensitization on day 1 of OIT, all subjects reached a cumulative dose of $992 \mathrm{mg}$ peanut flour, with minimal or no symptoms. Through the dose-escalation phase, 12 subjects reached a maximum maintenance dose of $4000 \mathrm{mg}$ peanut flour per day in a median 8-week period. In the final DBPCFC carried out between weeks 30 and 32 of therapy, these 12 subjects could tolerate 8000 mg peanut flour, and continued eating 10 to 20 peanuts daily without adverse health effects. This study was also performed with small a number of subjects and lacked placebo control. However, with $92 \%$ of the highly susceptible patients desensitized over a very short length of time, with minimal symptoms, these findings further substantiate the promise of anti- IgE + OIT combination.

The most recent addition to the reports on clinical trials of combination therapy describes the results of a single-center, phase I, open-label study in children with allergies to multiple foods. Having confirmed the safety and feasibility of OIT to confer desensitization to up to 5 allergens simultaneously in an independent phase I study [32], the authors investigated whether using anti-IgE as an adjunctive therapy to "multi-OIT" safely allows for a faster simultaneous desensitization to multiple allergens. Twenty-five 
participants who were enrolled based on failure in an initial DBPCFC were administered omalizumab every 2-4 weeks for 16 weeks. A single-day rush oral desensitization was carried out in the 9th week of omalizumab administration, where, subjects, under clinical supervision, consumed a mix of offending food allergens in increasing doses ranging from $5 \mathrm{mg}$ to $1250 \mathrm{mg}$ of total food allergen protein at defined time intervals. During this rush desensitization, 19 of the total 25 participants tolerated the highest dose with minimal or no rescue therapy. All of the participants were started on their highest tolerated dose as their initial daily home dose, which was escalated every 2 weeks or at a later point based on the participant's allergic reactions and safety outcomes. With this protocol, the participants reached their maintenance dose of $4000 \mathrm{mg}$ protein per allergen at a median of 18 weeks. The reported adverse reaction rate during home dosing was $5.3 \%$, with $94 \%$ of reactions being mild [33••]. Given that $30 \%$ of children with food allergy are sensitized to multiple foods, and in their case, the desensitization to each allergen individually could take many years, the multi-OIT protocol certainly holds great promise. Further benefit in the study was accentuated with antiIgE adjunctive therapy, where the target maintenance dose was reached

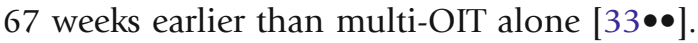

Each of these combination therapy studies was carried out with children, in contrast to monotherapy studies, where most of the participants were adults.

While all these open-label pilot trials are highly encouraging and are novel in the domain of food allergy therapy, further multicenter, double-blind, placebocontrolled, phase II and III trials are needed to cement the findings, which can then be translated into clinical practice. Indeed, two such studies are underway, at Mount Sinai School of Medicine, New York (investigator: Dr. Hugh Sampson) and Duke University, North Carolina (investigator: Dr. Wesley Burks), comparing the safety and efficacy of omalizumab + OIT combination therapy in milk- and peanut-allergic patients, respectively (www.clinicaltrials.gov).

\section{Emerging trends and future directions}

Table 1 summarizes the outcomes of clinical trials employing anti-IgE in treating food allergy. Although highly limited, existing data highlight the superior performance of anti-IgE and OIT combination therapy over anti-IgE monotherapy or OIT alone [10, 12].

Suppression of basophil activation afforded by anti-IgE pretreatment clearly protects subjects from acute adverse reactions on initiation of OIT, thus enabling administration of high doses of food allergen and rapid dose escalation. This component affords combination therapy a distinct advantage over OIT alone, where desensitization must be carried out at a slower rate with relatively small doses.

Understanding the immunologic mechanism behind desensitization through each mode of desensitization is highly important, as the insight thus gained will guide the design of the most effective protocol for therapy. Unfortunately, current data in this regard are quite scarce. Certain studies on OIT have reported an increase in frequency and suppressive ability of Treg post-therapy [34,35]. The previously mentioned study by 


\begin{tabular}{|c|c|c|c|c|c|c|c|}
\hline Trial & Therapy & Allergen & $\begin{array}{l}\text { No. of } \\
\text { patients } \\
\text { enrolled } \\
\text { (in test } \\
\text { group) }\end{array}$ & $\begin{array}{l}\text { Allergen- } \\
\text { specific } \\
\text { IgE range } \\
\text { (kUA/L) }\end{array}$ & $\begin{array}{l}\text { Initial } \\
\text { DBPCFC } \\
\text { range } \\
(\mathrm{mg})\end{array}$ & $\begin{array}{l}\text { Final } \\
\text { DBPCFC } \\
\text { range } \\
(\mathrm{mg})\end{array}$ & $\%$ desensitized \\
\hline Leung (2003) & $\begin{array}{l}\text { TNX-901 } \\
\quad(450 \mathrm{mg})\end{array}$ & Peanut & 21 & $0.69-100$ & 178 & 2,805 & 24 \\
\hline Sampson (2011) & Omalizumab & Peanut & 9 & $7.1-323$ & $<5$ to 100 & $50-8,000$ & 11 \\
\hline Savage (2012) & Omalizumab & Peanut & 14 & $1.1-184$ & $10-700$ & $1,830-10,000$ & 29 \\
\hline Nadeau (2011) & $\begin{array}{l}\text { Omalizumab } \\
\quad+0 \mathrm{IT}\end{array}$ & Milk & 11 & $41.6-342$ & Not done & 8,000 & 82 \\
\hline Schneider (2013) & $\begin{array}{l}\text { Omalizumab } \\
\quad+0 \mathrm{IT}\end{array}$ & Peanut & 13 & $21-617$ & $\leq 100$ & 8,000 & 92 \\
\hline Bégin (2014) & $\begin{array}{l}\text { Omalizumab } \\
+ \text { multi- } \\
\text { OIT }\end{array}$ & $\begin{array}{l}\text { Multiple } \\
\qquad(2 \text { to } 5)\end{array}$ & 25 & $2-256$ & $\leq 182$ & $\begin{array}{l}\text { 4,000 per allergen } \\
\text { (maintenance } \\
\text { dose reached) }\end{array}$ & 100 \\
\hline
\end{tabular}

Bedoret et al. is the only reference point at present to understand the mechanistic details behind anti-IgE + OIT combination therapy. This study shows depletion of Th2-polarized cells and/or deviation toward

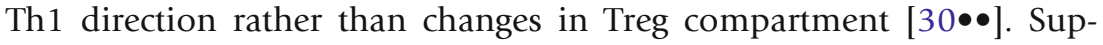
pression of basophil activity, the trend toward decreased allergen-specific $\mathrm{IgE}$, and a significant increase in allergen-specific IgG4 are common findings, irrespective of therapeutic mode (Fig. 1b). An interesting consideration of the contribution of high vs. low, dose in driving $\mathrm{T}$ cell anergy vs. suppression that was put forth by Bedoret et al. warrants further in-depth investigation [36]. In addition, the possibility of generation of tolerogenic DCs and other changes among innate immune cells, and the induction of tolerance reflected by circulating immune cells vs. that in the gut-resident population are some of the interesting questions worth addressing through future research.

Clinical outcome and concomitant immunologic analysis of samples of subjects undergoing trials based on a uniform, well-designed protocol for omalizumab monotherapy, or OIT, vis-à-vis omalizumab + OIT combination therapy will be of great value in the appraisal of relative efficacy.

As is the case with most OIT studies, the fact remains that studies with combination therapy thus far have focused on desensitization alone and not on long-term tolerance wherein a desensitized subject continues not to react to the previously offending allergen even after a phase of complete avoidance of potentially allergenic foods. Results from protocols that follow desensitized subjects post-avoidance phase are anticipated, and would be truly conclusive in determining the "curative" potential of oral immunotherapy.

An important consideration is that with the cost of a 150-mg vial of omalizumab over $\$ 500$, anti-IgE adjunctive therapy remains a pricy treatment option. Nevertheless, since desensitization through combination ther- 
apy is achieved at a much faster rate, it would spare the cost of extra visits

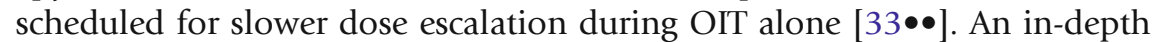
pharmacoeconomic analysis in this context will certainly be helpful for a concrete feasibility check.

It should be mentioned that the high affinity of IgE-FceRI interaction $\left(\mathrm{K}_{\mathrm{d}} \sim 1 \mathrm{nM}\right)$ limits the action of omalizumab, since it can bind only to free IgE and cannot effectively block activation through IgE pre-bound to FceRI. Improving upon the existing monoclone and finding natural inhibitors or designing synthetic ones that can disrupt IgE-FceRI binding has been a challenge, although some of the ongoing endeavors have yielded exciting results $[37,38]$. Candidate inhibitors of particular interest are designed ankyrin repeat proteins (DARPins), especially since one among these engineered proteins, DARPin E2_79, has been shown to disrupt IgEFceRI interaction through facilitated dissociation [39]. Further testing will determine whether such inhibitors outperform anti-IgE in vivo and can eventually enter clinics.

Exploring the potential of anti-IgE in food allergy therapy is an active area of research. Results from trials with anti-IgE + OIT combination therapy, while limited in number and having certain drawbacks, show particular promise, concomitantly raising many questions and possibilities that have opened new avenues for investigators.

\section{Compliance with Ethics Guidelines}

\section{Conflict of Interest}

Monali Manohar and Kari C. Nadeau each declare that they have no conflict of interest.

\section{Human and Animal Rights and Informed Consent}

This article does not contain any studies with human or animal subjects performed by any of the authors.

\section{References and Recommended Reading}

Papers of particular interest, published recently, have been highlighted as:

- Of importance

$\bullet \quad$ Of major importance

1. Boyce JA, Assa'ad A, Burks AW, Jones SM, Sampson $\mathrm{HA}$, et al. Guidelines for the diagnosis and management of food allergy in the United States: summary of the NIAID-Sponsored expert panel report. Nutr Res. 2011;31:61-75.

2. Holgate ST, Polosa R. Treatment strategies for allergy and asthma. Nat Rev Immunol. 2008;8:218-30.

3. Sicherer SH, Sampson HA. Food allergy: epidemiology, pathogenesis, diagnosis, and treatment. J Allergy Clin Immunol. 2014;133:291-307.e295.
4. Galli SJ, Tsai M. IgE and mast cells in allergic disease. Nat Med. 2012;18:693-704.

5. MacGlashan DW. IgE-dependent signaling as a therapeutic target for allergies. Trends Pharmacol Sci. 2012;33:502-9.

6. Syed A, Kohli A, Nadeau KC. Food allergy diagnosis and therapy: where are we now? Immunotherapy. 2013;5:931-44.

7. Bégin P, Nadeau KC. Diagnosis of food allergy. Pediatr Ann. 2013;42:102-9. 
8. Henson M, Burks AW. The future of food allergy therapeutics. Semin Immunopathol. 2012;34:703-14.

9. Gupta R, Holdford D, Bilaver L, Dyer A, Holl JL, et al. THe economic impact of childhood food allergy in the united states. JAMA Pediatr. 2013;167:1026-31.

10. Nadeau KC, Kohli A, Iyengar S, DeKruyff RH, Umetsu DT. Oral immunotherapy and Anti-IgE antibody-adjunctive treatment for food allergy. Immunol Allergy Clin N Am. 2012;32:111-33.

11. Khoriaty E, Umetsu DT. Oral immunotherapy for food allergy: towards a new horizon. Allergy Asthma Immunol Res. 2013;5:3-15.

12. Wang J, Sampson H. Oral and sublingual immunotherapy for food allergy. Asian Pac J Allergy Immunol. 2013;31:198-209.

13. Wang J, Patil SP, Yang N, Ko J, Lee J, et al. Safety, tolerability, and immunologic effects of a food allergy herbal formula in food allergic individuals: a randomized, double-blinded, placebo-controlled, dose escalation, phase 1 study. Ann Allergy Asthma Immunol. 2010;105:75-84.

14. Patil SP, Wang J, Song Y, Noone S, Yang N, et al. Clinical safety of Food Allergy Herbal Formula-2 (FAHF-2) and inhibitory effect on basophils from patients with food allergy: extended phase I study. J Allergy Clin Immunol. 2011;128:1259-65.

15. Gould HJ, Sutton BJ. IgE in allergy and asthma today. Nat Rev Immunol. 2008;8:205-17.

16. Shields R, Whether W, Zioncheck K, O'Connell L, Fendly B, et al. Inhibition of allergic reactions with antibodies to IgE. Int Arch Allergy Immunol. 1995; 107:308-12.

17. Kolbinger F, Saldanha J, Hardman N, Bendig MM. Humanization of a mouse anti-human IgE antibody: a potential therapeutic for IgE-mediated allergies. Protein Eng. 1993;6:971-80.

18. Vichyanond P. Omalizumab in allergic diseases, a recent review. Asian Pac J Allergy Immunol. 2011;29:209-19.

19. MacGlashan DW, Bochner BS, Adelman DC, Jardieu PM, Togias A, et al. Down-regulation of

Fc(epsilon)RI expression on human basophils during in vivo treatment of atopic patients with anti-IgE antibody. J Immunol. 1997;158:1438-45.

20. Holgate S, Smith N, Massanari M, Jimenez P. Effects of omalizumab on markers of inflammation in patients with allergic asthma. Allergy. 2009;64:1728-36.

21. van Neerven RJJ, van Roomen CPAA, Thomas WR, de Boer M, Knol EF, et al. Humanized Anti-IgE mAb Hu901 prevents the activation of allergen-specific T cells. Int Arch Allergy Immunol. 2001;124:400-2.

22. Segal M, Stokes JR, Casale TB. Anti-Immunoglobulin E therapy. World Allergy Org J. 2008;1:174-83.

23. Leung DYM, Sampson HA, Yunginger JW, Burks AW, Schneider LC, et al. Effect of Anti-IgE therapy in patients with peanut allergy. $\mathrm{N}$ Engl J Med. 2003;348:986-93.
This is the first study reporting efficacy of anti-IgE (talizumab) in the treatment of food allergy.

24. Sampson HA, Leung DYM, Burks AW, Lack G, Bahna $\mathrm{SL}$, et al. A phase II, randomized, double blind, parallel group, placebo controlled oral food challenge trial of Xolair (omalizumab) in peanut allergy. J Allergy Clin Immunol. 2011;127:1309-10.

Although this study has limited data owing to early termination, it serves as the only referene point for a placebocontrolled omalizumab monotherapy trial in treating patients with peanut allergy.

25.• Savage JH, Courneya J-P, Sterba PM, MacGlashan DW, Saini SS, et al. Kinetics of mast cell, basophil, and oral food challenge responses in omalizumabtreated adults with peanut allergy. J Allergy Clin Immunol. 2012;130:1123-9.

This report uncovers interesting kinetic and mechanistic details behind desensitization through omalizumab monotherapy.

26. MacGlashan Jr DW, Savage JH, Wood RA, Saini SS. Suppression of the basophil response to allergen during treatment with omalizumab is dependent on 2 competing factors. J Allergy Clin Immunol. 2012;130:1130-5.

27. Gernez Y, Tirouvanziam R, Yu G, Ghosn EEB, Reshamwala N, et al. Basophil CD203c levels are increased at baseline and can be used to monitor omalizumab treatment in subjects with nut allergy. Int Arch Allergy Immunol. 2011;154:318-27.

28. Casale TB, Busse WW, Kline JN, Ballas ZK, Moss MH, et al. Omalizumab pretreatment decreases acute reactions after rush immunotherapy for ragweed-induced seasonal allergic rhinitis. J Allergy Clin Immunol. 2006;117:134-40.

$29 . \bullet \quad$ Nadeau KC, Schneider LC, Hoyte L, Borras I, Umetsu DT. Rapid oral desensitization in combination with omalizumab therapy in patients with cow's milk allergy. J Allergy Clin Immunol. 2011;127:1622-4.

This is the first open-label pilot study demonstrating efficacy of anti-IgE as an adjunctive therapy with OIT in children with milk allergy.

$30 . \bullet$ Bedoret D, Singh AK, Shaw V, Hoyte EG, Hamilton R, et al. Changes in antigen-specific T-cell number and function during oral desensitization in cow's milk allergy enabled with omalizumab. Mucosal Immunol. 2012;5:267-76.

This report represents an excellent reference for understanding the immune mechanism behind anti-IgE + OIT combination therapy.

31.• Schneider LC, Rachid R, LeBovidge J, Blood E, Mittal M, et al. A pilot study of omalizumab to facilitate rapid oral desensitization in high-risk peanut-allergic patients. J Allergy Clin Immunol. 2013;132:1368-74.

This report demonstrates efficacy of anti-IgE + OIT combination therapy in treating peanut-allergic children, thus endorsing previous findings from milk study.

32. Bégin $P$, Winterroth LC, Dominguez T, Wilson $S$, Bacal L, et al. Safety and feasibility of oral immuno- 
therapy to multiple allergens for food allergy. Allergy Asthma Clin Immunol. 2014;10:1.

33.• Bégin P, Dominguez T, Wilson SP, Bacal L, Mehrotra A, et al. Phase 1 results of safety and tolerability in a rush oral immunotherapy protocol to multiple foods using omalizumab. Allergy Asthma Clin Immunol. 2014;10:7.

This recent open-label phase I study is the first to demonstrate safe and efficeint administration of anti-IgE + OIT combination therapy in simultanous desensitization to multiple food allergens.

34. Jones SM, Pons L, Roberts JL, Scurlock AM, Perry TT, et al. Clinical efficacy and immune regulation with peanut oral immunotherapy. J Allergy Clin Immunol. 2009;124:292-300.

35. Varshney P, Jones SM, Scurlock AM, Perry TT, Kemper A, et al. A randomized controlled study of peanut oral immunotherapy: clinical desensitization and modulation of the allergic response. J Allergy Clin Immunol. 2011;127:654-60.

36. Rachid R, Umetsu D. Immunological mechanisms for desensitization and tolerance in food allergy. Semin Immunopathol. 2012;34:689-702.

37. Smith LD, Leatherbarrow RJ, Spivey AC. Development of small molecules to target the IgE:FceRI protein-protein interaction in allergies. Future Med Chem. 2013;5:1423-35.

38. Jackman J, Chen Y, Huang A, Moffat B, Scheer JM, et al. Development of a two-part strategy to identify a therapeutic human bispecific antibody that inhibits IgE receptor signaling. J Biol Chem. 2010;285:20850-9.

39. Kim B, Eggel A, Tarchevskaya SS, Vogel M, Prinz H, et al. Accelerated disassembly of IgE-receptor complexes by a disruptive macromolecular inhibitor. Nature. 2012;491:613-7. 